\title{
Flower-shaped gold nanoparticles synthesized using Kedrostis foetidissima and their antiproliferative activity against bone cancer cell lines
}

\author{
M. Jannathul Firdhouse ${ }^{1} \cdot$ P. Lalitha ${ }^{1}$
}

Received: 3 April 2015/Accepted: 21 September 2016/Published online: 28 September 2016

(c) The Author(s) 2016. This article is published with open access at Springerlink.com

\begin{abstract}
Three different methods were employed for the synthesis of biogenic gold nanoparticles using the aqueous extracts of Kedrostis foetidissima. The interaction of gold nanoparticles with the phytoconstituents was investigated by FTIR. The complete reduction of chloroaurate ions to gold nanoparticles was monitored using UV-visible spectroscopy under the different plant extract concentration and conditions. The formation of gold nanoparticles was confirmed using XRD, SEM and TEM analysis. The anisotropic and flower-shaped gold nanoparticles of size below $25 \mathrm{~nm}$ was confirmed by TEM analysis. Cucurbitacins, the chief constituents of $K$. foetidissima probably might have interacted with the chloroaurate ions, facilitating the formation of gold nanoparticles. KFL-mediated AuNPs showed $88 \%$ cell viability against bone cancer cell lines at $200 \mu \mathrm{g} / \mathrm{ml}$ concentration using MTT assay. This may be due to the formation of flower-shaped nature of KFL-mediated AuNPs. The novelty of the work lies in the plantmediated synthesis of biocompatible gold nanoparticles of size less than $25 \mathrm{~nm}$ showing $88 \%$ of cell viability against bone cancer cell lines.
\end{abstract}

Keywords Kedrostis foetidissima . Gold nanoparticles . UV-Visible $\cdot$ SEM $\cdot$ XRD $\cdot$ TEM

P. Lalitha

goldenlalitha@gmail.com

1 Department of Chemistry, Avinashilingam Institute for Home Science and Higher Education for Women University, Coimbatore 641043, Tamil Nadu, India

\section{Introduction}

In modern science, one of the most dynamic areas of research is found to be in nanotechnology field which creates a force towards human life [1]. Nanochemistry mainly focuses on the synthesis of various metal nanoparticles like gold, silver, zinc, platinum [2-5], etc., due to its unique properties, which opens a new venue for the production of nanodevices, therapeutics, drugs, etc., in the field of nanomedicine and nanobiotechnology [6-12]. Gold nanoparticles have diverse applications in cancer treatment, electrochemical sensors, biosensors, gene and drug delivery, catalysis, etc., [13, 14].

The superior properties of the metal nanoparticles depend upon the size, shape and dispersed nature which is different from that of the bulk materials. Nanoparticles can be prepared by physical and chemical methods. Vapour deposition and exfoliation are the physical method of synthesis, whereas hazardous chemicals are used as starting materials in most of the chemical methods of synthesis. Hence, the eco-friendly synthetic procedures for nanoparticles have been adopted by researchers $[15,16]$.

In the biosynthetic method, plant extracts, bacteria, fungi, etc., are used as reductants for the synthesis of metal nanoparticles. The nanoparticles synthesized using plant extracts are more stable and the rate of synthesis is also rapid than the microorganisms. Plants have been exploited for the large scale synthesis of nanoparticles due to its accessibility and loaded source of secondary metabolites which serve as reducing and capping agents. Gold nanoparticles synthesized using plant extracts have received much attention due to its enhanced conductivity, ability to transfer electrons, catalytic and antimicrobial activities [17-20].

In the past few years, non-spherical gold nanoparticles such as rods, wires, cubes, nanocages, triangular prisms and 
other interesting structures such as hollow tubes, capsules, even branched nanocrystals have garnered significant attention in research. These unsymmetrical nanoparticles strongly differ from those of symmetric, spherical gold nanoparticles due to their unique and fine-tuned properties. Their improved mechanical, optical and electronic properties and specific surface-enhanced spectroscopies make them ultimate structures for budding applications in electronics, photonics, optical sensing and imaging, biomedical labeling and sensing, catalysis and electronic devices among others [21].

Spherical, oval and other polyhedral gold nanoparticles have been synthesized using three different plant extracts Angelica, Hypericum, and Hamamelis [22]. An excellent electrocatalytic activity towards the oxidation of methanol and the reduction of oxygen was achieved by gold nanoflowers (GNFs) synthesized using N-2-hydroxyethylpiperazine-N-2-ethanesulphonic acid (HEPES) in one-pot synthesis [23]. Exploration of the optical properties of those triangular particles has shown that the surface plasmon bands frequency is strongly sensitive to the corner sharpness. Simulations by Discrete Dipolar Approximation (DDA) approach qualitatively indicate that the electric field is mainly associated with the particle corners [24].

Osteosarcoma, the most common primary malignant bone tumour, usually arises in the metaphysis of long bones such as the distal femur, proximal tibia and proximal humerus during the second decade (60-80 years) of life. Overall, osteosarcoma has an incidence rate of 10-26 per million new cases worldwide each year [25]. Various side effects such as severe nausea, vomiting, nephrotoxicity, myelosuppression and neurotoxicity were noted after cisplatin administration, whereas gastrointestinal disturbances, acute nausea, vomiting, stomatitis, alopecia baldness, neurologic disturbances, bone marrow, aplasia, cumulative cardio toxicity and bone marrow depressant effects due to doxorubicin administration [26]. Because of these shortcomings, effective approaches with less or no side effects should be considered. Glycogenic AuNPs have been found to be active against human osteosarcoma cell line (Saos2) with an $\mathrm{IC}_{50}$ of $0.187 \mathrm{mM}$ [27].

In developing countries, traditional plants have served huge source of medicine, due to their observed antibacterial and antiproliferative properties. Kedrostis foetidissima, belongs to Cucurbitaceae family and its characteristic constituents are cucurbitacins, tetracyclic triterpenoids, with varied pharmacological activities. Miro [28] and Rios et al. [29] reported the presence of cucurbitacins B, D, E and $\mathrm{I}$ in $K$. foetidissima. A significant level of cytotoxicity was also observed by $K$. foetidissima on both MCF-7 and YMB-1 cell lines [30]. Biosynthesis of silver nanoparticles using $K$. foetidissima [31] and its antimicrobial activities [32] are reported. The presence of metabolites like terpenoids in the above extracts as noted from phytochemical colour tests, prompted us to utilize these extracts for this study.

In our present study, gold nanoparticles was synthesized using the aqueous extracts of $K$. foetidissima by three different conditions viz. room temperature, higher temperature and sonication. The synthesized KFL-mediated AuNPs were tested for their antiproliferative activity against bone cancer (MG-63) cell lines.

\section{Materials and methods}

Chloroauric acid $\left(\mathrm{HAuCl}_{4}\right)$ was purchased from Loba chemicals, India. Fresh plant (K. foetidissima) was collected from a local area in Coimbatore district, Tamil $\mathrm{Nadu}$, India. The voucher specimen was submitted to Botanical Survey of India, Southern Regional Centre, Tamil Nadu Agricultural University, Coimbatore, Tamil Nadu and the Specimen was identified as K. foetidissima (jacq.) cogn, Cucurbitaceae family and authenticated (BSI/ SRC/5/23/2010-11/Tech-1309).

\section{Extraction of plant}

The fresh leaves and stem parts of $K$. foetidissima were labelled as KFL and KFS, respectivley, $(20 \mathrm{~g})$ were weighed, washed thoroughly thrice with distilled water and cut into fine pieces, then $100 \mathrm{ml}$ of Millipore water was added and boiled for $5 \mathrm{~min}$ in a $500 \mathrm{ml}$ Erlenmeyer flask. The prepared solutions were filtered using Whatmann filter paper No. 42 to remove the plant debris, sonicated for $15 \mathrm{~min}$ and refrigerated at $-4{ }^{\circ} \mathrm{C}$ for further studies. This filtrate obtained (designated as aqueous extract) was used within a week for the synthesis of nanoparticles to avoid the annihilation of phytoconstituents.

\section{Phytochemical screening test}

The phytochemical screening of leaf and stem extract of $K$. foetidissima was done according to standard procedures [33, 34].

\section{Synthesis of gold nanoparticles}

Different concentrations of aqueous extracts (KFL and KFS) in the ratio $1: 1,2: 1,3: 1,4: 1$ and 5:1 were mixed with $3 \mathrm{mM} \mathrm{HAuCl}_{4}$ solution at room temperature $\left(28-30{ }^{\circ} \mathrm{C}\right)$. The aqueous extracts (KFL and KFS) were kept constant $(1 \mathrm{ml})$ and treated with different concentrations (1, 2, 3, 4 and $5 \mathrm{ml}$ ) of gold chloride solutions and kept at room temperature (RT). The colour change from pale green to violet colour characteristic of gold nanoparticles was indicative of its formation. The $\lambda_{\max }$ value was recorded 
using a spectrophotometer. Similar experiment was repeated by sonicating the mixture using an ultrasonic bath [PCI Ultrasonics $1.5 \mathrm{~L}(\mathrm{H})](\mathrm{SN})$. In another set of experiments, the mixture was heated to higher temperature $\left(75^{\circ} \mathrm{C}\right)(\mathrm{HT})$ and the time of formation of gold nanoparticles was recorded, as evidenced from the violet colour formation.

\section{Separation of gold nanoparticles}

The violet coloured gold nanoparticles solution was centrifuged at 13,000 rpm for $15 \mathrm{~min}$ in a centrifuge (Spectrofuge $7 \mathrm{M}$ ) twice, to remove the plant cell debris. The supernatant solution obtained after centrifugation was analyzed by XRD, SEM and TEM.

\section{Characterization techniques}

UV-Visible absorption spectra were measured using Double beam spectrophotometer 2202-(SYSTRONICS). The crystallite size of synthesized gold nanoparticles was examined by X-ray diffraction analysis (X' pert powder PANalytical) with a $\mathrm{Cu} \mathrm{K} \alpha$ radiation monochromatic filter in the range $10^{\circ}-80^{\circ}$. The crystallite size of gold nanoparticles was calculated using Debye-Scherrer's equation:

$D=k \lambda / \beta \cos \theta$

where, $k$ is dimensionless constant; $\lambda$ is wavelength of $\mathrm{X}$-ray $(\AA) ; \beta$ is angular FWHM of the XRD peak at the diffraction angle (radian); and $\theta$ is diffraction angle (degrees).

The topography and morphology of gold nanoparticles were investigated by scanning electron microscope using TESCAN instrument provided with Vega TC software. The FTIR spectrum (FTIR-8400S, Shimadzu) was also recorded for the synthesized gold nanoparticles. Transmission electron microscopy (TEM) offers high resolution of particle size, shape and also dispersity. The nanodimension of the synthesized AuNPs was established through recording TEM images using FEI's Tecnai G2 Transmission Electron Microscope.

\section{Antiproliferative activity of biosynthesized AuNPs against bone cancer cell lines-MTT assay}

The cell lines MG-63 (Human Osteosarcoma) were obtained from National Centre for Cell Science (NCCS), Pune, India and grown-up in Eagles Minimum Essential Medium.

\section{Cancer cell treatment procedure}

The monolayer cells were separated with trypsin-ethylene diamine tetraacetic acid to formulate single cell suspensions and feasible cells were counted using a hemocytometer and diluted with medium enclosing $5 \%$ FBS to provide final density of $1 \times 10^{5}$ cells $/ \mathrm{ml}$. The cell suspensions ( $100 \mu \mathrm{l} /$ well) were seeded into 96 -well plates at plating density of 10,000 cells/well and incubated to allow for cell attachment at $37{ }^{\circ} \mathrm{C}, 5 \% \mathrm{CO}_{2}, 95 \%$ air and $100 \%$ humidity. After $24 \mathrm{~h}$ the cells were treated with serial concentrations of the test samples (KFL-mediated AuNPs). The tested samples were initially dissolved in DMSO and twofold series dilutions were made to get the desired test concentration $(12.5,25,50,100$ and $200 \mu \mathrm{g} /$ $\mathrm{ml}$ ) in serum free medium for KFL-mediated AuNPs. Aliquots of different sample dilutions were added to suitable wells already containing $100 \mu \mathrm{l}$ medium. Following sample addition, the plates were incubated at $37{ }^{\circ} \mathrm{C}$ for $48 \mathrm{~h}$ at $100 \%$ relative humidity, $95 \%$ air and $5 \% \mathrm{CO}_{2}$. The medium without samples was taken as control. The study was run in triplicate to ensure accuracy of the results.

\section{MTT assay}

3-[4, 5-Dimethylthiazol-2-yl $]$ 2,5-diphenyltetrazolium bromide (MTT), a yellow water soluble tetrazolium salt gets converted to an insoluble purple formazan by the mitochondrial enzyme in existing cells, succinate-dehydrogenase. The quantity of formazan produced is unswervingly proportional to the number of viable cells. After forty-eight hours of incubation, $15 \mu \mathrm{l}$ of MTT $(5 \mathrm{mg} /$ $\mathrm{ml}$ ) in PBS (phosphate buffered saline) was added to each well and incubated at $37^{\circ} \mathrm{C}$ for $4 \mathrm{~h}$. The medium with MTT was then flicked off and the formed formazan crystals were solubilized in $100 \mu \mathrm{l}$ DMSO and absorbance was measured at $570 \mathrm{~nm}$ using a micro plate reader.

\section{Calculation}

The percentage cell inhibition was determined using the formula:

$$
\begin{aligned}
\% \text { Cell inhibition }= & 100 \\
& -\mathrm{ABS}(\text { sample }) / \mathrm{ABS}(\text { control }) \\
& \times 100 .
\end{aligned}
$$

A nonlinear regression graph was plotted between percentage cell inhibition and $\log _{10}$ concentration. The $\mathrm{IC}_{50}$ value was determined using GraphPad Prism software.

\section{Results and discussion}

The phytochemical screening of KFL and KFS extracts revealed the presence of secondary metabolites like alkaloids, flavonoids, saponins, steroids and primary metabolites like proteins and glycosides. The aqueous extracts of 
Table 1 Comparison of time of formation of AuNPs synthesized using KFL extracts at different conditions

\begin{tabular}{|c|c|c|c|c|c|c|c|c|}
\hline \multirow[t]{2}{*}{ S. no } & \multirow{2}{*}{$\begin{array}{l}\text { Concentration of KFL } \\
\text { extracts }+\mathrm{HAuCl}_{4}(\mathrm{ml})\end{array}$} & \multicolumn{3}{|c|}{ Time of formation (min) } & \multirow{2}{*}{$\begin{array}{l}\text { Concentration of KFL } \\
\text { extracts }+\mathrm{HAuCl}_{4}(\mathrm{ml})\end{array}$} & \multicolumn{3}{|c|}{ Time of formation (min) } \\
\hline & & RT & HT & $\mathrm{SN}$ & & RT & HT & SN \\
\hline 1. & $1+1$ & 40 & 5 & 5 & $1+1$ & 40 & 5 & 5 \\
\hline 2. & $1+2$ & 60 & 15 & 10 & $2+1$ & 30 & 18 & 15 \\
\hline 3. & $1+3$ & 90 & 20 & 15 & $3+1$ & 25 & 25 & 20 \\
\hline 4. & $1+4$ & 120 & 20 & 15 & $4+1$ & 10 & 30 & 25 \\
\hline 5. & $1+5$ & 180 & 25 & 20 & $5+1$ & 15 & 35 & 25 \\
\hline
\end{tabular}

Table 2 Comparison of time of formation of AuNPs synthesized using KFS extracts at different conditions

\begin{tabular}{|c|c|c|c|c|c|c|c|c|}
\hline \multirow[t]{2}{*}{ S. no } & \multirow{2}{*}{$\begin{array}{l}\text { Concentration of KFS } \\
\text { extracts }+\mathrm{HAuCl}_{4}(\mathrm{ml})\end{array}$} & \multicolumn{3}{|c|}{ Time of formation $(\mathrm{min})$} & \multirow{2}{*}{$\begin{array}{l}\text { Concentration of KFS } \\
\text { extracts }+\mathrm{HAuCl}_{4}(\mathrm{ml})\end{array}$} & \multicolumn{3}{|c|}{ Time of formation (min) } \\
\hline & & RT & HT & $\mathrm{SN}$ & & RT & HT & $\mathrm{SN}$ \\
\hline 1. & $1+1$ & 120 & 15 & 15 & $1+1$ & 150 & 25 & 35 \\
\hline 2. & $1+2$ & 90 & 25 & 20 & $2+1$ & 120 & 25 & 30 \\
\hline 3. & $1+3$ & 60 & 25 & 25 & $3+1$ & 90 & 20 & 20 \\
\hline 4. & $1+4$ & 45 & 35 & 30 & $4+1$ & 60 & 15 & 15 \\
\hline 5. & $1+5$ & 45 & 35 & 30 & $5+1$ & 60 & 10 & 9 \\
\hline
\end{tabular}

KFL and KFS when treated with gold chloride solution produced a visible colour change from pale green to violet colour after $60 \mathrm{~min}$. The colour change was observed rapidly in the highest concentration $(5 \mathrm{ml})$ of KFL and KLS extracts (Tables 1, 2). The varied concentrations $(1-5 \mathrm{ml})$ of KFL extracts with $1 \mathrm{ml}$ of gold chloride solution produce AuNPs within 20-30 min (Table 1). It was noted that the rate of synthesis of gold nanoparticles increases as the concentration of KFS extracts increases as in sonication, room and higher temperature methods (Table 2).

Comparing the variation in the concentration of KFL and KFS extracts and gold chloride solution reveals the increase in the concentration of aqueous extracts to decrease the time taken for the formation of AuNPs. This may be due to the presence of more constituents and less metal ions in the mixture. Hence, rapid synthesis of AuNPs was obtained with different concentrations of gold chloride solution compared to variation of the plant extract concentration. The plant $K$. foetidissima as a whole is a rich source of cucurbitacins as reported earlier and the phytochemical screening also revealed the presence of terpenoids $[28,29]$. This revealed that the phytoconstituents present in the extracts are responsible for the rapid reduction of chloroaurate ions to gold nanoparticles.

Plant-mediated synthesis of AuNPs reveal increase in concentration of plant extract cause agglomeration in AuNPs. As the temperature is increased, more and more of gold chloride is reduced, leading to an increase in the formation of gold nanoparticles using both KFL and KFS extracts. This is due to the enhanced activation of chloroaurate ions which quickens the formation of gold nanoparticles. The time variation in the interaction of chloroaurate ions with the metabolites present in the extracts can be overcome by the sonication method compared to the other methods employed in the present synthesis.

The rate of reduction of chloroaurate ions to be managed using KFL and KFS extracts under different conditions is in the order:

Sonication $>$ Higher temperature $>$ Room temperature

This may be due to the acoustic cavitations produced by ultrasound irradiation which enhances the reduction of metal ions with addendum from increase in temperature and hence the rate of synthesis than the conventional method. It was observed that the ultrasound technique aids the reaction rate and simplifies the synthetic methods of novel materials. Hence, the dispersion produced by the cavitational motion may facilitate the interaction of metabolites present in the aqueous extracts with the chloroaurate ions aiding gold nanoparticles formation.

\section{UV-Visible spectroscopy}

UV-Visible spectroscopy is a good analytical tool which authenticates the complete formation and stability of gold nanoparticles. The UV-visible spectra (Fig. 1) of gold 
Fig. 1 UV-visible spectra of gold nanoparticles synthesized using the solvent extracts (KFL and KFS) of Kedrostis

foetidissima under sonication
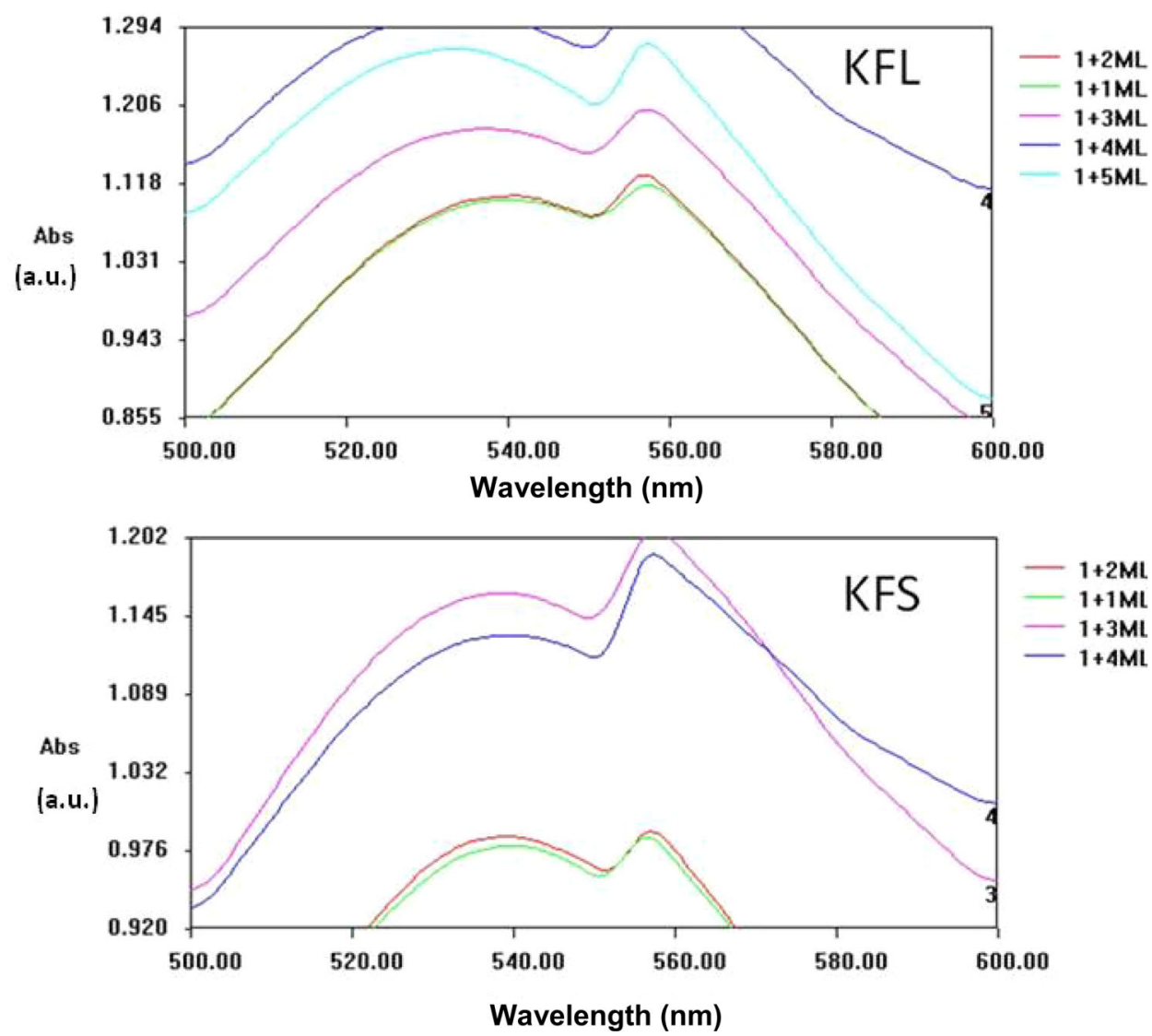

nanoparticles shows a broad absorption band at 510-600 nm. The appearance of a broad SPR band from 510 to $550 \mathrm{~nm}$, with a sharp band at $570 \mathrm{~nm}$ signifies the presence of large and polyshaped gold nanoparticles. The intensity of the bands increases with extract concentration. At the highest concentration $(5: 1)$ of plant extracts (KFL and KFS), the intensity of the band starts to decrease, implying the dominant nature of the phytoconstituents. The shape and position of the bands remain the same under different conditions, which may be due to the adsorption of phytoconstituents onto the surface of chloroaurate ions through Vander Waal's forces. The synthesized gold nanoparticles were stable withstanding the colour of the solution for 30 days, prompting us to explore its application as chemotherapeutic drugs.

\section{XRD analysis}

The crystalline nature of the synthesized gold nanoparticles was analyzed by X-ray diffractometer. Figure 2 represents the XRD patterns of the synthesized gold nanoparticles coated on a glass substrate. The diffraction peaks at $38^{\circ}$, $44^{\circ}, 64^{\circ}, 77^{\circ}$ which were indexed to the face-centered cubic lattice was observed for the extracts (KFL and KFS) under room temperature (KFLRT and KFSRT) and sonication (KFLSN and KFSSN), respectively. There is little difference in the diffraction peaks and full-width half maximum values, but the crystallite size $10.6 \mathrm{~nm}$ was observed in both extracts under room temperature and sonication, respectively. The additional peak at $28^{\circ}$ may be due to the presence of phytoconstituents capped onto the synthesized AuNPs. The determination of crystallite size of the gold nanoparticles using Debye-Scherrer's equation is given in Table 3.

\section{SEM analysis}

To determine the shape, size and distribution of the nanoparticles, SEM Images were also recorded. The SEM analysis confirmed the synthesized gold nanoparticles to be in nanometer size. They were spherical in shape and the size of the gold nanoparticles found to be uniformly distributed (Fig. 3). The size of the gold nanoparticles varies in SEM compared to that of XRD analysis. This may be due to the capping nature of the phytoconstituents as the time increases from the day of synthesis. It was noted that in room temperature condition the crystallite size is $90 \mathrm{~nm}$, whereas it reduced to $50 \mathrm{~nm}$ in sonication due to the fine dispersion produced by the ultrasonic irradiation. 


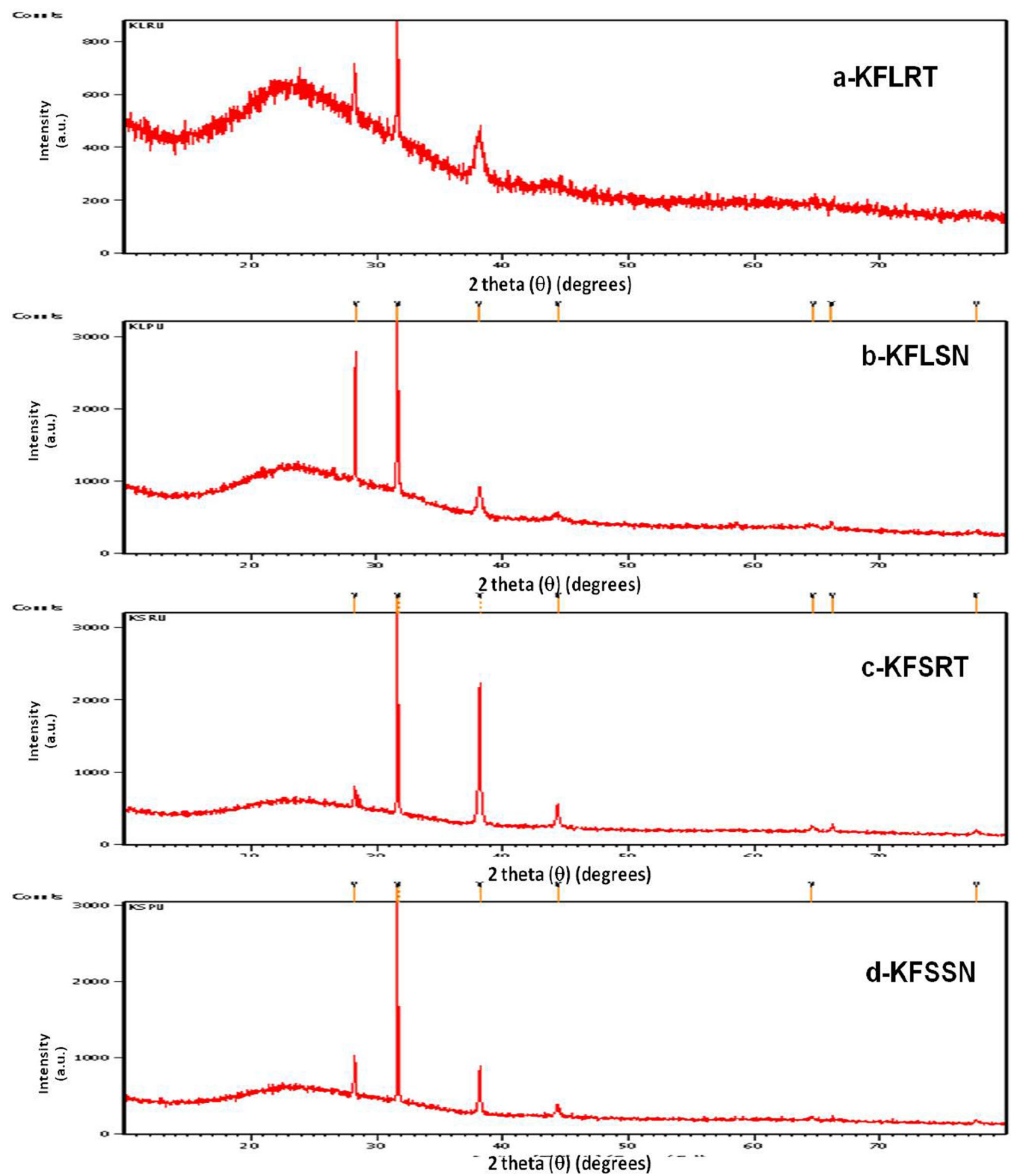

Fig. 2 XRD patterns of the synthesized gold nanoparticles using the KF extracts under room temperature (KFLRT and KFSRT) and sonication (KFLSN and KFSSN) 
Table 3 Determination of crystallite size of gold nanoparticles synthesized using extracts (KFL and KFS) under room temperature and sonication

\begin{tabular}{|c|c|c|c|c|c|c|}
\hline S. no & Sample & $2 \theta$ (degrees) & $\operatorname{Cos} \theta$ & $\beta=\pi^{*} \mathrm{FWHM} / 180$ (radians) & $D=k \lambda / \beta \cdot \operatorname{Cos} \theta(\mathrm{nm})$ & Average size $(\mathrm{nm})$ \\
\hline \multirow[t]{4}{*}{1.} & \multirow[t]{4}{*}{ KFLRT } & 38.1224 & 0.94517 & 0.01648 & 8.90 & \multirow[t]{4}{*}{10.6} \\
\hline & & 44.4012 & 0.92600 & 0.16149 & 9.27 & \\
\hline & & 64.6879 & 0.84507 & 0.01473 & 11.14 & \\
\hline & & 77.7243 & 0.77933 & 0.01359 & 13.09 & \\
\hline \multirow[t]{4}{*}{2.} & \multirow[t]{4}{*}{ KFLSN } & 38.1216 & 0.94517 & 0.01648 & 8.90 & \multirow[t]{4}{*}{10.6} \\
\hline & & 44.3707 & 0.92600 & 0.16149 & 9.27 & \\
\hline & & 64.6438 & 0.84507 & 0.01473 & 11.14 & \\
\hline & & 77.6067 & 0.77933 & 0.01359 & 13.09 & \\
\hline \multirow[t]{4}{*}{3.} & \multirow[t]{4}{*}{ KFSRT } & 38.1616 & 0.94506 & 0.01648 & 8.90 & \multirow[t]{4}{*}{10.6} \\
\hline & & 44.3498 & 0.92606 & 0.01615 & 9.27 & \\
\hline & & 64.6068 & 0.84526 & 0.01474 & 11.13 & \\
\hline & & 77.5398 & 0.77977 & 0.01359 & 13.08 & \\
\hline \multirow[t]{4}{*}{4.} & \multirow[t]{4}{*}{ KFSSN } & 38.1686 & 0.94506 & 0.01648 & 8.90 & \multirow[t]{4}{*}{10.6} \\
\hline & & 44.3738 & 0.92593 & 0.01614 & 9.28 & \\
\hline & & 64.5678 & 0.84544 & 0.01474 & 11.13 & \\
\hline & & 77.5923 & 0.77933 & 0.01359 & 13.09 & \\
\hline
\end{tabular}

\section{TEM analysis}

The AuNPs synthesized using K. foetidissima leaf extract was found to be less than $50 \mathrm{~nm}$ as obtained from SEM analysis and hence it was further analyzed for TEM. Kedrostis foetidissima $(1 \mathrm{ml})$ sonicated with chloroaurate ions (3 ml) for $15 \mathrm{~min}$ results in purple gold nanoparticles were chosen for TEM analysis. The TEM micrographs shows the formation of anisotropic (triangular plate, spherical, hexagon) gold nanoparticles of size less than $25 \mathrm{~nm}$ (Fig. 4a, b). Figure $4 c, d$ showed the formation of flower-shaped gold nanoparticles. The arrow in Fig. 4d indicates the encapsulation of AuNPs with the protein moiety present in $K$. foetidissima leaf extract. Hence the proteins in the leaf extract of $K$. foetidissima act as a capping and stabilizing agent. The flower-shape gold nanoparticles are synthesized without the use of toxic chemicals and stabilizers.

Literature survey revealed synthesis of biological triangular gold nanoprisms by the reduction of aqueous chloroaurate ions by extracts of Cymbopogon flexuosus in high yield at room temperature [35]. Tamarind leaf extract can also be used as the reducing agent for making gold nanotriangles [36]. Diverse shapes of nanoparticles such as hexagon, truncated triangle and triangle can also be synthesized using the extract of seaweed, Sargassum sp., at room temperature. The growth of nanoparticles may be assisted by the capping agents which limits the size and controls the shape. The non-specific nature of binding on all exposed surfaces of gold may lead to the anisotropic growth [37].

Irregular surfaces and round edges of non-spherical nanoparticles possess more surface area than spherical particles with smooth surfaces. Hence the binding capacity of these particles to cancerous cells and tissues will be enhanced due to their surface area and extended residence times in vivo [38]. The rearrangement and aggregation of the smaller particles results in anisotropic triangular structures. The fabrication of anisotropic nanoparticles can be facilitated by the low rate of reduction, room temperature and sometimes with slight modifications in the temperature. This nanostructure remains no longer as triangular nanoprisms, when significant rounding occurs and gets transformed into nanodisks or hexagonal nanoprisms. Due to their aforesaid reasons, different shapes of gold nanoparticles using $K$. foetidissima extracts obtained in this study is justified.

\section{FTIR analysis}

Figure 5a, b represents the FTIR spectra of the plant extracts (KFL and KFS) and synthesized gold nanoparticles (KFL-mediated AuNPs and KFS-mediated AuNPs). In KFL extract, the band at $1638 \mathrm{~cm}^{-1}$ may be due to the presence of a carbonyl group. The two bands at $2926 \mathrm{~cm}^{-1}$ corresponds to the stretching vibrations of the $-\mathrm{C}-\mathrm{H}$ bond and $3345 \mathrm{~cm}^{-1}$ may be assigned to $-\mathrm{OH}$ group (Fig. 5a). In KFS extract, the bands at 1639 and $3336 \mathrm{~cm}^{-1}$ corresponds to the carbonyl and hydroxyl group, respectively. An another band at $2931 \mathrm{~cm}^{-1}$ may be due to the $-\mathrm{C}-\mathrm{H}$ bond stretching frequencies (Fig. 5b). The absence and shift of the aforesaid bands indicate that the metabolites like triterpenoids might have been responsible for the reduction of gold to gold nanoparticles 


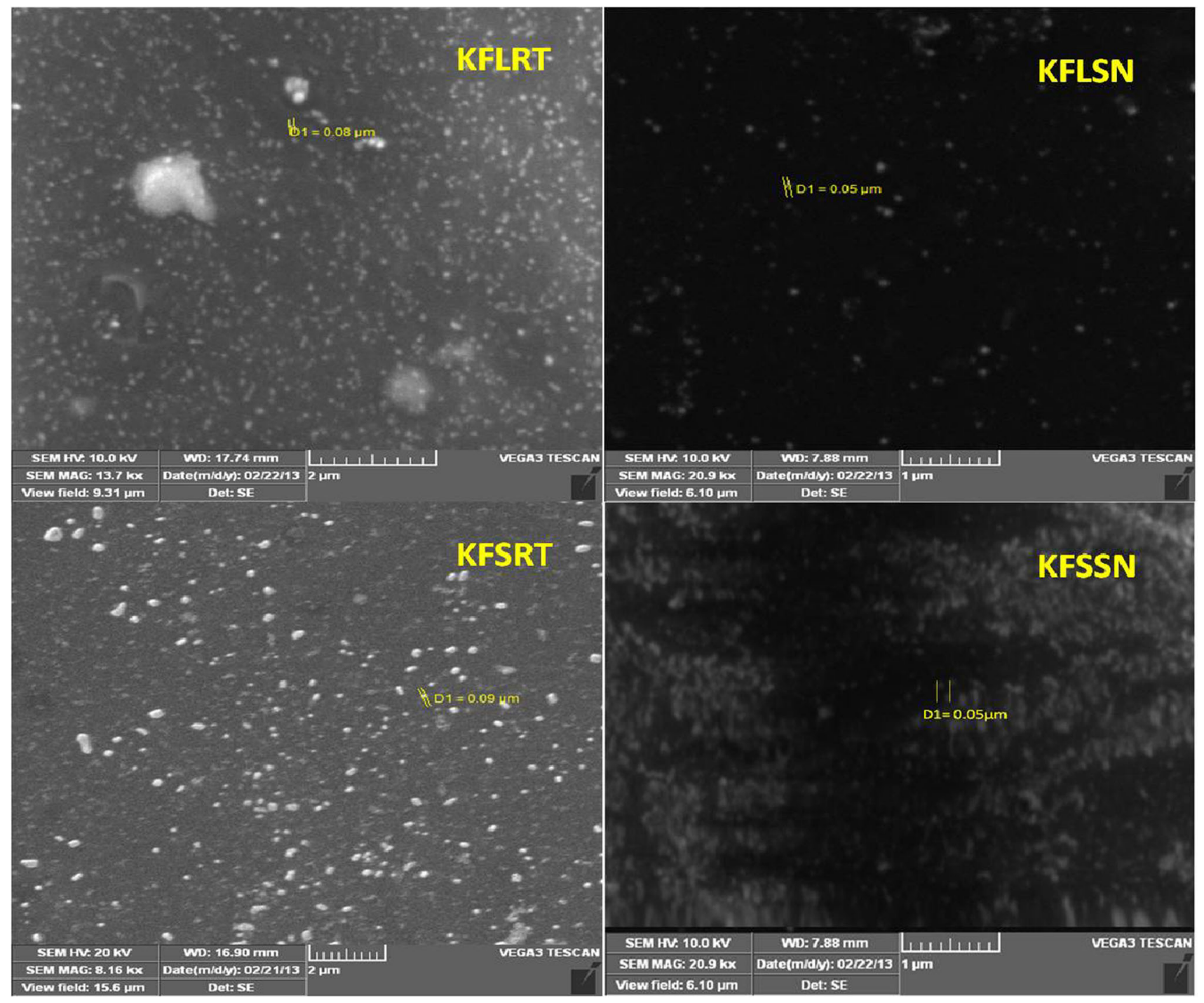

Fig. 3 SEM micrographs of the synthesized gold nanoparticles under room temperature and sonication using the extracts (KFL and KFS)

in Fig. 5 (a-KFL-mediated AuNPs and b-KFS-mediated AuNPs).

\section{Antiproliferative study-MTT assay}

The antiproliferative activity of KFL-mediated AuNPs under in vitro conditions was examined against human osteosarcoma cell lines (MG-63) by MTT assay. The histogram plot of MTT assay results for cell viability studies of MG-63 cell lines after exposing to varying concentrations of KFL-mediated AuNPs was shown in Fig. 6. The red bars correspond to the \% cell viability at the given concentration of AuNPs. The plots clearly show $88 \%$ cell viability for the bone cancer cells that were treated with $200 \mu \mathrm{g} / \mathrm{ml}$ concentration of KFL-mediated AuNPs for $24 \mathrm{~h}$ (Fig. 6). The borohydride-reduced gold nanoparticles show nearly $80 \%$ cell viability at the exposure to $100 \mu \mathrm{M}$ concentration for $24 \mathrm{~h}$. Gold nanotriangles synthesized using the leaf extract of lemon grass plant do not show any cellular toxicity to non-phagocytotic cancerous cells while the gold salt precursor showed acute toxicity to the cells. Thus, it inferred that biogenic gold nanotriangles are more biocompatible than chemically synthesized gold nanoparticles [39]. In the present work, the MG-63 cells also show almost $100 \%$ viability after exposure to $25 \mu \mathrm{g} / \mathrm{ml}$ concentration of flower-shaped gold nanoparticles for $24 \mathrm{~h}$. It can be concluded that the KFL-mediated AuNPs do not show acute toxicity even at high concentrations taken in the present study revealing the biocompatibility.

As concentration increases from 12.5 to $200 \mu \mathrm{g} / \mathrm{ml}$, the cell viability gets decreased indicates the anitproliferative activity of KFL-mediated AuNPs on MG-63 cell lines. The results revealed that the flower-shaped KFL-mediated AuNPs may be the reason for the less toxic nature against 

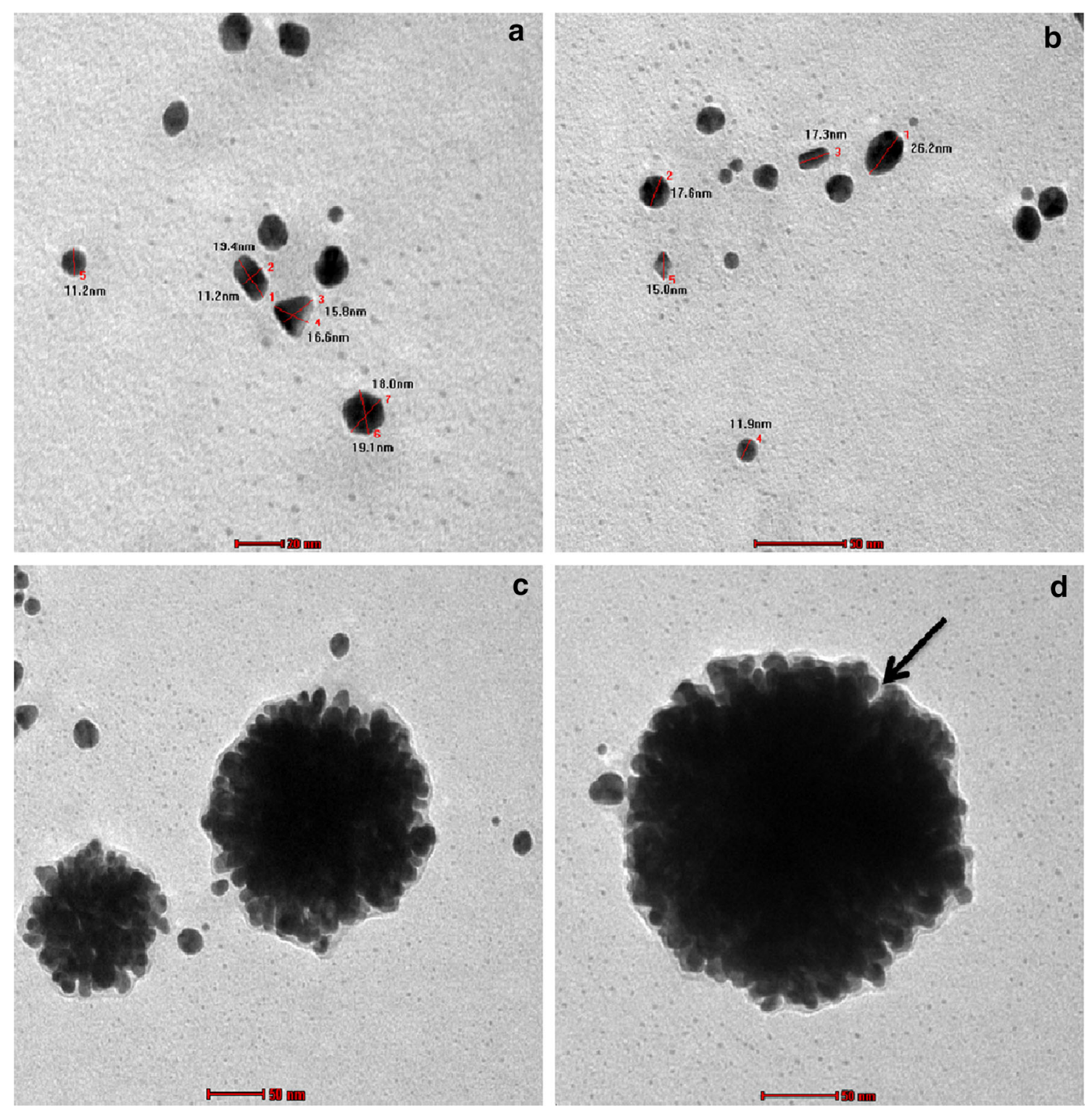

Fig. 4 TEM micrographs of the anisotropic gold nanoparticles viz. (a) triangular plate and hexagon, spherical and rod, (b) and flower-shaped AuNPs (c, d) synthesized under sonication using KFL extract

MG-63 cell lines. This present results suggest that the gold nanoparticles do not show any cellular toxicity to cancerous as well as non-cancerous cells at concentration $50 \mu \mathrm{g} /$ ml. Cytotoxicity also depends on the type of cells used. Pioneering studies on nanoparticles show that non-spherical shapes show great promise as cancer drug delivery vectors. Filamentous or worm-like micelles together with other rare morphologies such as needles or disks may become the norm for next-generation drug carriers [40]. Resv-Dox mixtures and Dox-GNPs complexes mediate the anticancer activity of Dox at very low concentration $(0.1 \mu \mathrm{g} / \mathrm{ml})$ against $\mathrm{HeLa}$ and CaSki cells [41].

Figure 7 shows the slight changes in the morphology of cells and a decrease in the number at $200 \mu \mathrm{g} / \mathrm{ml}$ concentration of KFL-mediated AuNPs on MG-63 cell lines. Further tests such as apoptosis assays can aid in the elucidation of the cellular mechanism of cell death. The results suggest the antiproliferative activity of the KFLmediated AuNPs may be due to the presence of anticancer molecules like cucurbitacins present in these extracts. Meat-ball like AuNPs developed using green tea extract under microwave irradiation are reported to be biocompatible up to $500 \mu \mathrm{g} / \mathrm{mL}$ against MCF-7 and HeLa cell lines [42]. The cytotoxic activity of the synthesized nanosilver using A. sessilis studied against PC-3 [43] and MCF-7 [44] cell lines by MTT assay was found to show significant activity, but $A$. sessilis-mediated AuNPs was non-toxic against MCF-7 cell lines [45]. Thus, the previous 


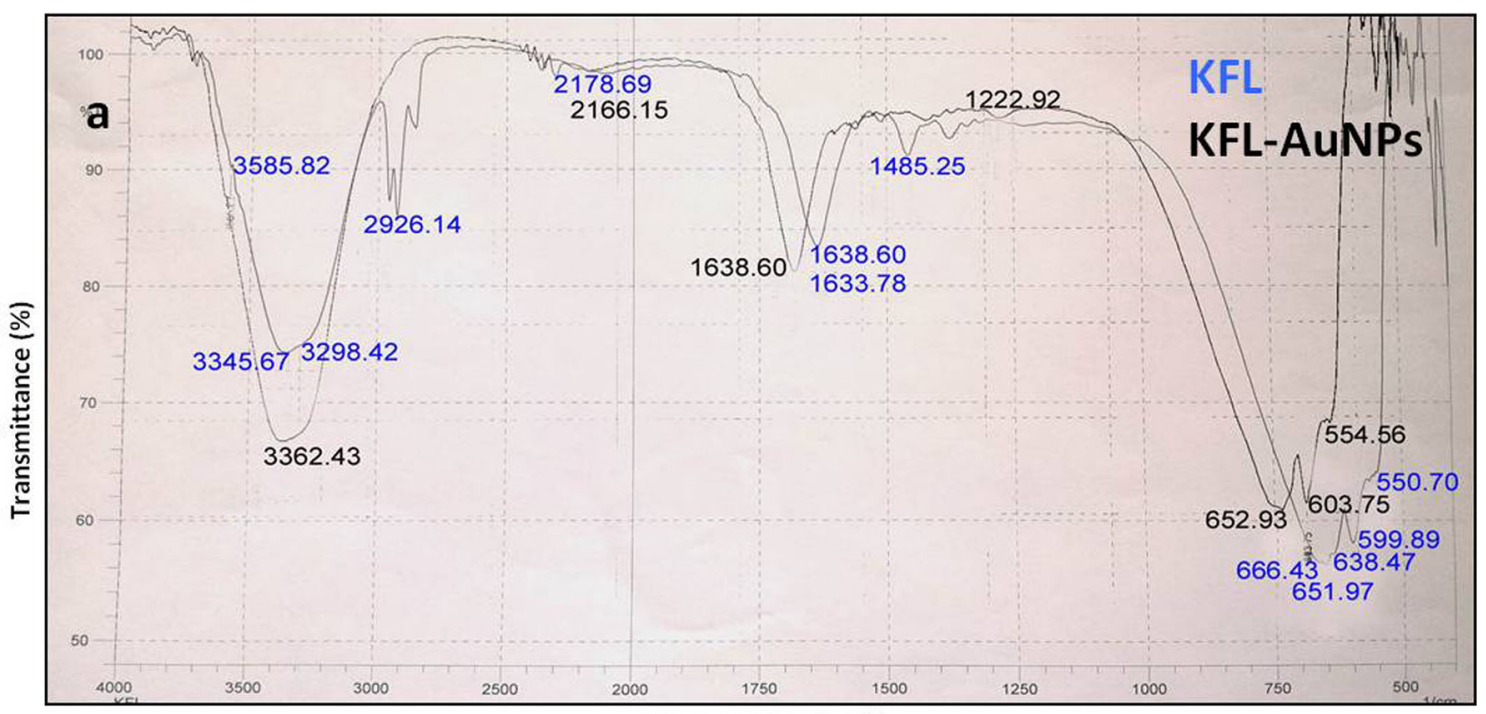

Wavenumber $\left(\mathrm{cm}^{-1}\right)$

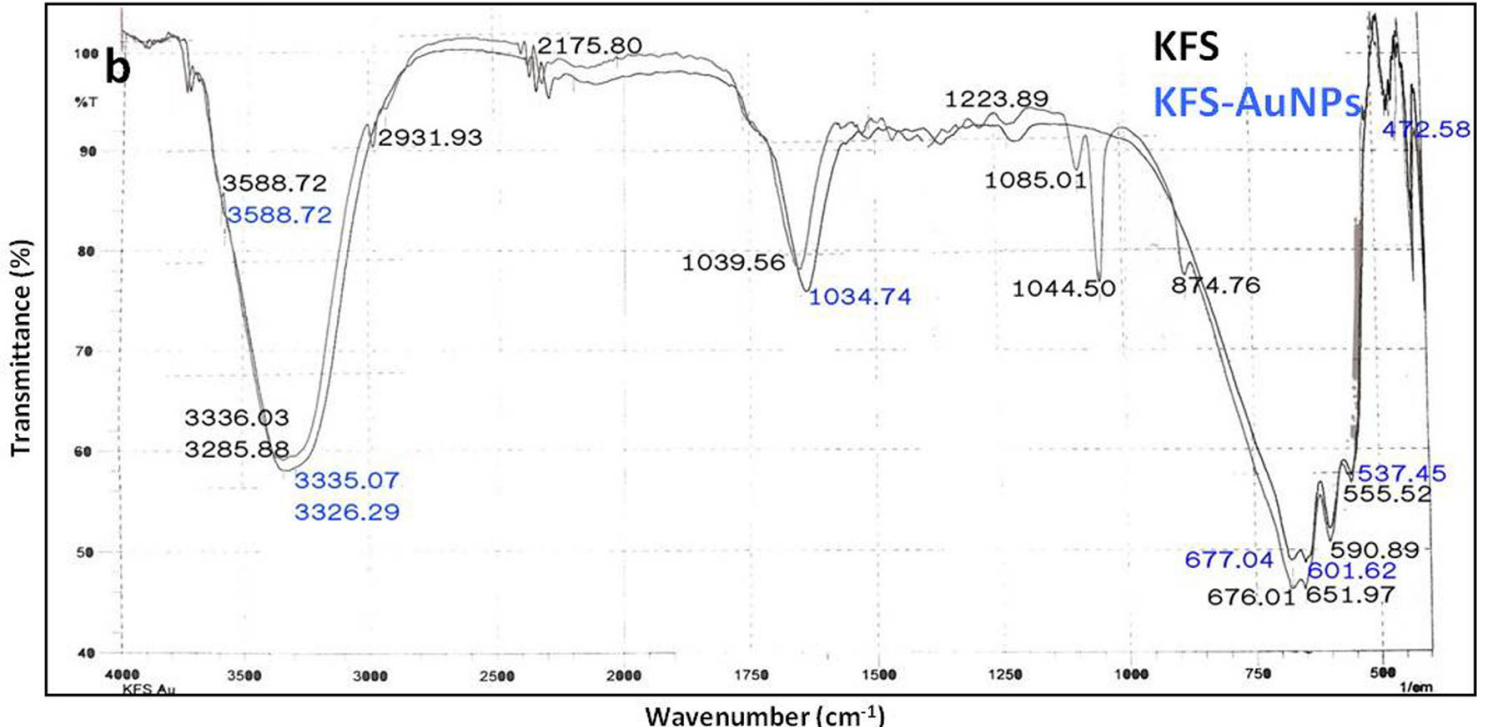

Fig. 5 FTIR spectra of the plant extracts (KFL and KFS) and synthesized gold nanoparticles (KFL-mediated AuNPs and KFS-mediated AuNPs)

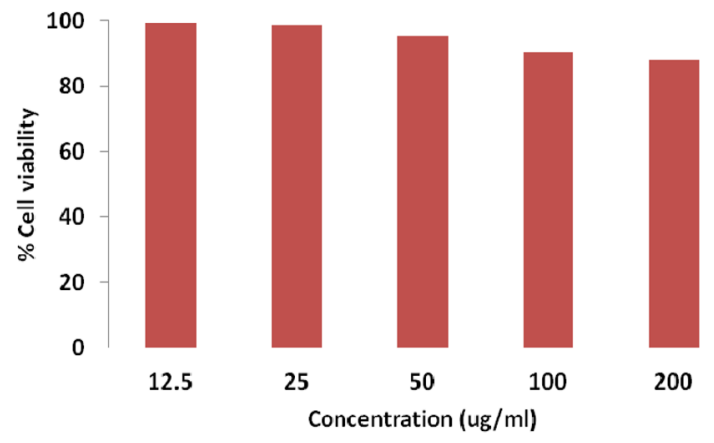

Fig. 6 Histogram of cell viability studies of MG-63 cell lines at various concentrations of KFL-mediated AuNPs

literature revealed that the cytotoxicity depends upon the nature of the capping agents and also the metal. The nontoxic nature of the biogenic gold nanoparticles provides new opportunities for the safe application in molecular imaging and therapy.

\section{Conclusion}

In this study, the aqueous extracts of KFL and KFS was tested for the reduction of chloroaurate ions to gold nanoparticles. The formation of the stable gold nanoparticles was confirmed by SPR band obtained in the UV-visible spectroscopy. The crystalline nature of the gold nanoparticles was revealed by the presence of diffraction peaks in the XRD patterns. The gold nanoparticles were spherical in shape and uniformly distributed as confirmed by SEM analysis. Gold nanoparticles below $50 \mathrm{~nm}$ size were anisotropic and flower shaped as confirmed from 

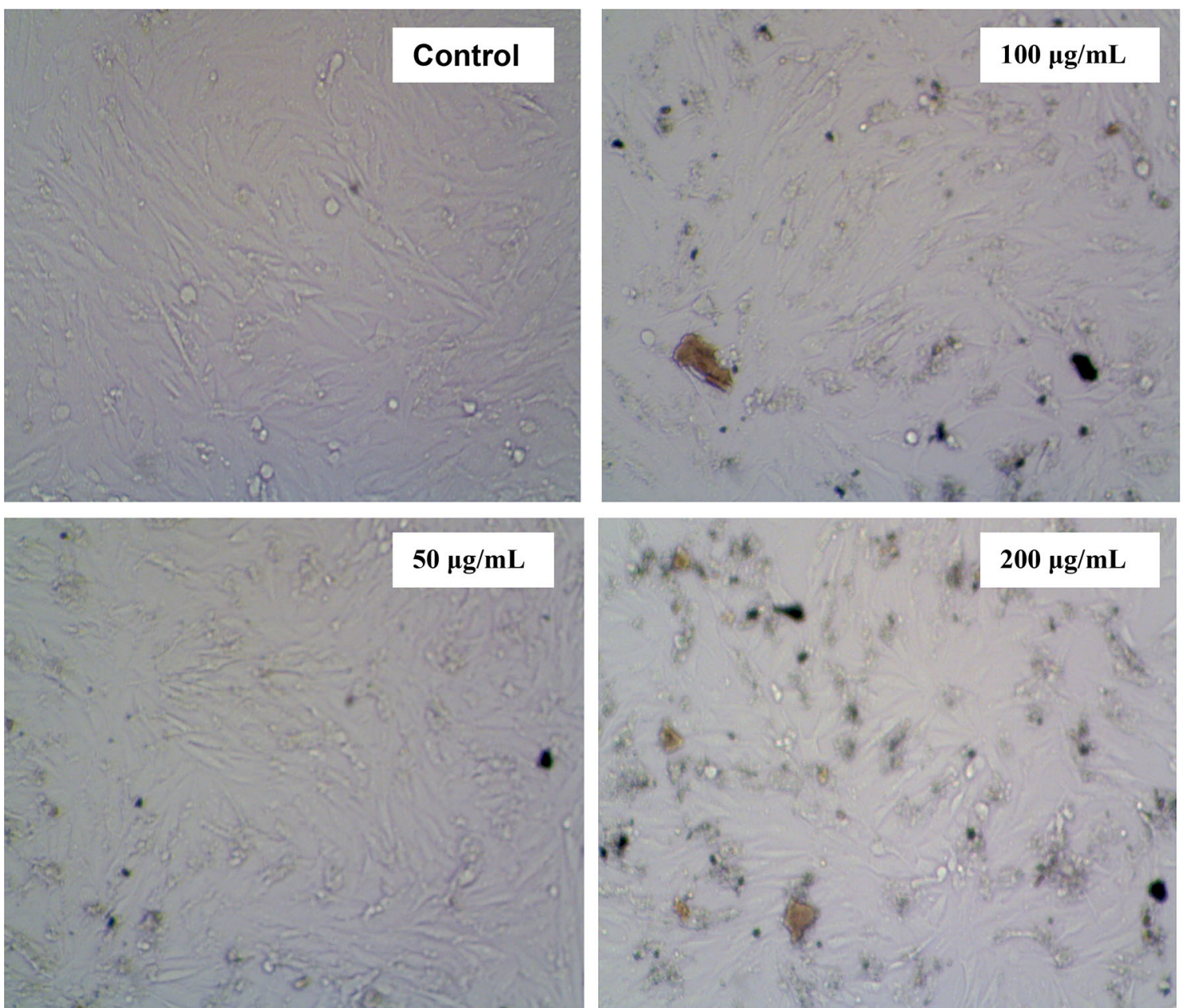

Fig. 7 Cytomorphological changes and growth inhibition of AuNPs synthesized using KFL extracts at different concentrations on MG-63 cell lines

TEM analysis. FTIR measurements revealed that the phytoconstituents can serve as an excellent reducing and capping agents. The results of the cell viability studies of KFLmediated AuNPs revealed the antiproliferative activity of AuNPs to depend on the size, shape and the nature of capping agents. Thus, the biogenic gold nanoparticles may find applications in the treatment of cancer.

Acknowledgments The authors sincerely thank the Avinashilingam Institute for Home Science and Higher Education for Women University, Coimbatore, Tamil Nadu, for providing research facilities, Department of Physics, Avinashilingam University for Women, for recording XRD, Periyar Maniammai University for recording SEM and TNAU, Coimbatore for recording TEM and $\mathrm{KMCH}$ College of Pharmacy for certifying anticancer activity of test samples.

Open Access This article is distributed under the terms of the Creative Commons Attribution 4.0 International License (http://creative commons.org/licenses/by/4.0/), which permits unrestricted use, distribution, and reproduction in any medium, provided you give appropriate credit to the original author(s) and the source, provide a link to the Creative Commons license, and indicate if changes were made.

\section{References}

1. Bhattacharya R, Mukherjee P (2008) Biological properties of "naked" metal nanoparticles. Adv Drug Deliv Rev 60:1289-1306. doi:10.1016/j.addr.2008.03.013

2. Ghule K, Ghule AV, Liu JY, Ling YC (2006) Microscale size triangular gold prisms synthesized using Bengal gram beans (Cicer arietinum L.) extract and $\mathrm{HAuCl}_{4} \times 3 \mathrm{H}_{2} \mathrm{O}$ : a green biogenic approach. J Nanosci Nanotechnol 6:3746-3751

3. Li S, Shen Y, Xie A, Yu X, Qiu L, Zhang L (2007) Green synthesis of silver nanoparticles using Capsicum annuиm L. extracts. Green Chem 9:852-858. doi:10.1039/B615357G

4. Song JY, Eun YK, Beom SK (2009) Biological synthesis of platinum nanoparticles using Diopyros kaki leaf extract. Bioproc Biosyst Eng 3:159-164. doi:10.1007/s00449-009-0373-2

5. Yan S, Wen H, Caiyun S (2009) The biomimetic synthesis of zinc phosphate nanoparticles. Dyes Pigm 80:254-258. doi:10.1016/j. dyepig.2008.06.010

6. Weller H (1993) Colloidal semiconductor Q-particles: chemistry in the transition region between solid state and molecules. Angew Chem Int Ed 32:41-53. doi:10.1002/anie.199300411

7. Henglein A (1993) Physicochemical properties of small metal particles in solution: "microelectrode" reactions, chemisorption, 
composite metal particles and the atom-to-metal transition. J Phys Chem 97:5457-5471. doi:10.1021/j100123a004

8. Alivisatos AP (1996) Semiconductor clusters, nanocrystals and quantum dots. Science 271:933-937

9. Colvin VL, Schlamp MC, Alivisatos AP (1994) Light-emitting diodes made from cadmium selenide nanocrystals and a semiconducting polymer. Nature 370:354-357. doi:10.1126/science. 271.5251 .933

10. Sastry M, Ahmad A, Khan MI, Kumar R (2003) Biosynthesis of metal nanoparticles using fungi and actinomycete. Curr Sci 85:162-170. Accessed 25 Jul 2003

11. Ahmad T, Wania IA, Manzoor N, Ahmed J, Asiri AM (2013) Biosynthesis, structural characterization and antimicrobial activity of gold and silver nanoparticles. Colloids Surf B 107:227-234. doi:10.1016/j.colsurfb.2013.02.004

12. Mocanu A, Horovitz O, Racz P, Tomoaia-Cotisel M (2015) Green synthesis and characterization of gold and silver nanoparticles. Rev Roum Chim 60(7-8):721-726

13. Schrinner M, Polzer F, Mei Y, Lu Y, Haupt B, Ballauff M (2007) Mechanism of the formation of amorphous gold nanoparticles within spherical polyelectrolyte brushes. Macromol Chem Phys 208:1542-1547. doi:10.1002/macp.200700161

14. Doria G, Conde J, Veigas B, Giestas, L, Almedia C, Assuncao M, Rosa J, Baptista P (2012) Noble metal nanoparticles for biosensing applications. J Drug Deliv 1657-1687. doi:10.3390/ s120201657

15. Parsons JG, Peralta-Videa JR, Gardea-Torresdey JL (2007) Use of plants in biotechnology: Synthesis of metal nanoparticles by inactivated plant tissues, plant extracts, and living plants. In: Sarkar D, Datta R, Hannigan R (eds) Developments in environmental science, vol. 5, Chapter 21. Elsevier, Minessota, pp $436-485$

16. Iravani S (2011) Green synthesis of metal nanoparticles using plants. Green Chem 13:2638-2650. doi:10.1039/c1gc15386b

17. Gan PP, Li SFY (2012) Potential of plant as a biological factory to synthesize gold and silver nanoparticles and their applications. Rev Environ Sci Biotechnol 11:169-206. doi:10.1007/s11157012-9278-7

18. Goyal RN, Gupta VK, Oyama M, Bachheti N (2007) Gold nanoparticles modified indium tin oxide electrode for the simultaneous determination of dopamine and serotonin: application in pharmaceutical formulations and biological fluids. Talanta 72:976-983. doi:10.1016/j.talanta.2006.12.029

19. Inbakandan D, Venkatesan R, Ajmal Khan S (2010) Biosynthesis of gold nanoparticles utilizing marine sponge Acanthella elongata (Dendy, 1905). Colloids Surf B 81:634-639. doi:10.1016/j. colsurfb.2010.08.016

20. Yan N, Xiao C, Kou Y (2010) Transition metal nanoparticles catalysis in green solvents. Coord Chem Rev 254:1179-1218. doi:10.1016/j.ccr.2010.02.015

21. Karuppaiya P, Satheeshkumar E, Chao WT, Kao LY, Chen EC, Tsay HS (2013) Anti-metastatic activity of biologically synthesized gold nanoparticles on human fibrosarcoma cell line HT1080. Colloids Surf B 110:163-170. doi:10.1016/j.colsurfb.2013. 04.037

22. Pasca RD, Mocanu A, Cobzac SC, Petean I, Horovitz O, Tomoaia-Cotisel M (2014) Biogenic syntheses of gold nanoparticles using plant extracts. Particul. Sci. Technol. 32(2):131-137

23. Jena BJ, Raj CR (2007) Synthesis of flower-like gold nanoparticles and their electrocatalytic activity towards the oxidation of methanol and the reduction of oxygen. Langmuir 23(7):4064-4070. doi:10.1021/la063243z

24. Kelly KL, Coronado E, Zhao LL, Schatz GC (2003) The optical properties of metal nanoparticles: the influence of size, shape, and dielectric environment. J Phys Chem B 107:668-677
25. Ando K, Heymann MF, Stresing V, Mori K, Rédini F, Heymann D (2013) Current therapeutic strategies and novel approaches in osteosarcoma. Cancers 5:591-616. doi:10.3390/cancers5020591

26. Khan AK, Rashid R, Murtaza G, Zahra A (2014) Gold nanoparticles: synthesis and applications in drug delivery. Trop J Pharma Res 13(7):1169-1177

27. Rahim M, Iram S, Khan MS, Khan MS, Shukla AR, Srivastava AK, Ahmad S (2014) Glycation-assisted synthesized gold nanoparticles inhibit growth of bone cancer cells. Colloids Surf B Biointerfaces 1(117):473-479. doi:10.1016/j.colsurfb.2013.12.008

28. Miro M (1995) Cucurbitacins and their pharmacological effects. Phytother Res 9:159-168. doi:10.1002/ptr.2650090302

29. Rios JL, Escandell JM, Recio MC (2005) New insights into the bioactivity of cucurbitacins. Stud Nat Prod Chem 32:429-469. doi:10.1016/S1572-5995(05)80062-6

30. Choene M, Motadi LR (2012) Anti-Proliferative effects of the methanolic extract of Kedrostis foetidissima in Breast cancer cell lines. Mol Biol 1(2):1-5. doi:10.4172/2168-9547.1000107

31. Amutha M, Firdhouse MJ, Lalitha P (2014) Biosynthesis of silver nanoparticles using Kedrostis foetidissima (Jacq.) Cogn J Nanotechnol 860875:5. doi:10.1155/2014/860875

32. Firdhouse MJ, Lalitha P (2014) Biocidal potential of biosynthesized silver nanoparticles against fungal threats. J Nanostruc Chem 5:25-33. doi:10.1007/s40097-014-0126-x-

33. Harborne JB (1973) Phytochemical methods: a guide to modern techniques of plant analysis. Chapman and Hall, New York, p 279

34. Raaman N (2006) Phytochemical techniques. New Indian Publishing Agencies, New Delhi, p 19

35. Shankar SS, Rai A, Ahmad A, Sastry M (2005) Controlling the optical properties of lemongrass extract synthesized gold nanotriangles and potential application in infrared absorbing optical coatings. Chem Mater 17:566-572

36. Ankamwar B, Chaudhary M, Sastry M (2005) Gold nanotriangles biologically synthesized using tamarind leaf extract and potential application in vapor sensing. Synth React Inorg Metals 35:19-26

37. Liu B, Xie J, Lee JY, Ting YP, Chen JP (2005) Optimization of high yield biological synthesis of single crystalline gold nanoplates. J Phys Chem B 109:15256-15263

38. Xue X, Wanga F, Liu X (2011) Emerging functional nanomaterials for therapeutics. J Mater Chem 21:13107-13127. doi:10. 1039/c1jm11401h

39 Singh A (2011) Metal nanoparticles in therapeutic and sensor applications. $\mathrm{PhD}$ thesis, University of Pune

40 Truong NP, Whittaker MR, Mak CW, Davis TP (2015) The importance of nanoparticle shape in cancer drug delivery. Expert Opin Drug Deliv 12(1):129-142. doi:10.1517/17425247.2014.950564

41 Tomoaia G, Horovitz O, Mocanu A, Nita A, Avram A, Racz CP, Soritau O, Cenariu M, Tomoaia-Cotisel M (2015) Effects of doxorubicin mediated by gold nanoparticles and resveratrol in two human cervical tumor cell lines. Colloids Surf B 135:726-734

42 Wu S, Zhou X, Yang X, Hou Z, Shi Y, Zhong L, Jiang Q, Zhang $\mathrm{Q}$ (2014) A rapid green strategy for the synthesis of Au "meatball' -like nanoparticles using green tea for SERS applications. J Nanopart Res 16(2325):1-13

43 Firdhouse MJ, Lalitha P (2013) Biosynthesis of silver nanoparticles using the extract of Alternanthera sessilis-antiproliferative effect against prostate cancer cells. Cancer Nano 4:137-143. doi:10.1007/s12645-013-0045-4

44 Firdhouse MJ, Lalitha P (2015) Apoptotic efficacy of biogenic silver nanoparticles on human breast cancer MCF-7 cell lines. Prog Biomater 4:113-121. doi:10.1007/s40204-015-0042-2

45 Firdhouse MJ, Lalitha P (2014) Cell viability studies of cubic gold nanoparticles synthesized using the extract of Alternanthera sessilis. World J Pharma Res 3(2):2868-2879 